\title{
Impact of Ethiopia's Productive Safety Net Programme (PSNP) on the Household Livelihood: The Case of Babile District in Somali Regional State, Ethiopia
}

\author{
Abduselam Abdulahi Mohamed \\ Department of Agricultural Economics, College of Agriculture and Veterinary Science, Ambo University, Ambo, Ethiopia \\ Email address: \\ abdisalan654@gmail.com,wwsale2010@gmail.com
}

To cite this article:

Abduselam Abdulahi Mohamed. Impact of Ethiopia's Productive Safety Net Programme (PSNP) on the Household Livelihood: The Case of Babile District in Somali Regional State, Ethiopia. International Journal of Economy, Energy and Environment.

Vol. 2, No. 2, 2017, pp. 25-31. doi: 10.11648/j.ijeee.20170202.12

Received: April 27, 2017; Accepted: May 13, 2017; Published: June 5, 2017

\begin{abstract}
This paper aspire in evaluating the impact of Ethiopia's productive safety net program on households' livelihood in Babile district by using primary data that were collected during January and February in 2017 from PSNP treatment and controls group sampled households. Descriptive statistics and Propensity Score Matching were used to evaluate the impact of the program in the study area. The paper revealed that among eleven model variables five of them influence the program participation decisions. Thus, the program had positive and highly significant effect on consumption in which 1269.11 Kcal was found due to the program intervention. Even though the result of the study shows that there is no significant difference among treatment and control groups in terms of annual income household participation in PSNP has positive and statistically significant effect on food consumption, so that on households' livelihood.
\end{abstract}

Keywords: Productive Safety Net Programme, Impact, Propensity Score Matching, Livelihood, Babile

\section{Introduction}

Ethiopian economy is highly dependent on agriculture and related activities. Agricultural sector single-handedly contributes more than 42 percent to the total gross domestic product (GDP), provides livelihood to about 80 percent of the country's population, about 85 percent rural employment opportunities comes from this sector, constitutes more than 80 percent of the nation's total exports, and supply most of the foreign exchange earnings to the national economy (United States Department of States, 2011). In addition to this agriculture is a main source of raw materials for industries. However, having such great significance in the national economy, the performance of the agriculture sector until recently has been depressing. The sector has encounter many challenges where Per capita food production has been declining and the rate of food production was lagged behind the population growth rate of the country derived from recurring drought and poor farming system in the country.

Currently, agriculture sector could not able to feed rapidly growing population of the country in which more than 27 million people become food insecure and total population of
18.1 million people require food assistance in 2016 due climate change and 2015 El Niño drought derived problems in the country which was the strongest droughts that have been recorded in the history of the nation's (Catley et al., 2016; cited in Abduselam, 2017).

The international community recently approved 2030 Agenda which is one of the priorities of alleviating food insecurity, as stated in Sustainable Development Goal 2: "End hunger, achieve food security and improved nutrition and promote sustainable agriculture". The region with the highest prevalence of food insecurity in which the agenda was mostly concentrated on is sub-Saharan African. Food insecurity is mostly widespread among rural households who have either no land or only small plots, and who live in conditions of extreme poverty. Traditional agricultural/ economic interventions alone are unlikely to generate substantial improvements, as they are rarely specifically targeted to the poor (DIE, 2016).

Climate related shocks affect productivity, hamper economic progress and exacerbate existing social and economic problems due to this food insecurity situation in Ethiopia is highly linked up to rigorous, recurring food 
shortage and famine, which are associated to recurrent climate change. Major steps have been taken in fighting food insecurity, poverty and bringing sustainable economic development in Ethiopia. In addition to this the Government has designed food security policies and strategies, which are basically community oriented and paying attention on addressing the needs of the poor households in terms of providing better social services (Abduselam A., 2017).

There is increasing interest in policies and interventions that improve the food security and livelihood conditions in the country. With the objective of addressing the underlying causes of vulnerability to food insecurity, the Government of Ethiopia launched its PSNP in 2005 as one component of a broader food security strategy including a Voluntary Resettlement Program and Other Food Security Programs (OFSP). The objective of the PSNP is to provide food/cash transfers to the food-insecure population in chronically foodinsecure districts in a way that prevents asset depletion at the household level and creates assets at the community level, improve their live and livelihood situations (MoARD, 2009).

The PSNP represents a serious and innovative attempt on the part of the Government of Ethiopia to move away from responding to chronic hunger through emergency appeals towards a more predictable response with predictable resources for expected community problems. The PSNP program is one of the flagship reform programmes developed by Ethiopian Government with other international funding agencies which represent significant transformation of the Government's policy and strategy for meeting the millennium Development Goal (MDG) to fight with poverty and hunger in Ethiopia (Mulugeta et al., 2006).

The overall goal of the program is to address predictable food insecurity through interventions designed to build household's capacity to resist and adopt with different shocks. In view of these considerations, in support of a continuation of the Program and building on the achievements and lessons learned from the different PSNP phases, the last phase of the program 2015-2020 (PSNP-4) was designed with the intended outcome of "Enhanced participation in improved rural safety net, livelihood and nutrition services by food insecure households" (MoARD, 2015).

Regarding targeting process of the program the PSNP uses a mix of geographic and community-based targeting to identify chronically food-insecure households. Initially, household-level targeting for the PSNP focused on selecting households that had high levels of food insecurity and that had been recipients of past emergency food aid. Having made the initial selection using the basic criteria, the program developers then verified and refined the selection of eligible households based on household livelihood capacity (assets and income). However, communities were given substantial discretion to modify this approach and to update their lists of food-insecure households annually based on local criteria this can give a chance for households those suddenly become more food-insecure as a result of a severe loss of assets and are unable to support themselves to be included in the beneficiary lists (Berhane et al., 2017).
A survey regarding the impact of PSNP on household's livelihood has not been yet evaluated, and remains untouched topic in the study area. The Propensity Score Matching (PSM) was used to evaluate impact of program by construct a comparison group and "matching" treatment households to comparison group households based on observable characteristics. The impact of the program is then estimated as the average difference between the outcome for each treatment household and a weighted average of outcomes in each similar comparison group of households from the matched sample.

\section{Methodology}

\subsection{Description of the Study Area}

Babile district (Babile Somali) is one of the eight districts of Fafen zone in Ethiopian Somali regional state. The district has a total population of 92,702 out of which 50059 are Male and 42643 are females. Regarding economic activities in which 70 percent are Agro-pastorals, 15 percent are Agrarian, 10 percent are pure Pastorals and 5 percent are petty traders. The average of household's size in Babile district is 7.5 (CSA, 2007).

Babile is one of the tourists attracting place in Easter part of the country. The district is rich in natural resources including hot springs, mineral water, Elephants Sanctuary and Daketa valley known for its variety of wildlife and astonishing rock formation. According to central statistics agency of Ethiopia, the population in Babile is mainly from Somali tribes', inhabited by the Karanle Hawiye clan of the Somali people which are Muslim in religion but some of the inhabitants are bilingual, speaking both Af-Somali and AfanOromo languages.

\subsubsection{Geographical Location of the District}

Babile was located at some $561 \mathrm{Km}$ to the east of AddisAbaba capital city of Ethiopia, $72 \mathrm{Km}$ to the west direction of Somali region's capital Jigjiga and $26 \mathrm{Km}$ to the East Harar. It is bordered by Gursum district in the North East, Goljono district in the East, Nogob (former Fik) Zone in the East and South, South West by Oromiya regional State. Babile in part it in compasses a plateau, as well as the lowland of the valleys of Erer, Daketa, Fafen, Gobele and Borale rivers; all being tributaries of Webi-Shabele. The district is located $70^{\circ} 90^{\prime \prime}$ North Latitude and $43^{\circ} 00^{\prime}$ East Longitude by having total land size of $1,325 \mathrm{~km}^{2}$ from which19, 823 Hectare has cultivable land; the annual rate of temperature is $26.5^{\circ}$ celsius with uneven rainfall distribution, and its attitude was estimated to be $800 \mathrm{M}-1500 \mathrm{M}$ above sea level (CSA, 2007).

\subsubsection{Basic Livelihood Characteristics in the District}

According to Somali regional state livelihood zone classification, Babile district is found under Jigjiga Agropastoral Livelihood Zone (LZ15). Rain-fed crop production is an important livelihood means in addition to livestock production. Main crops that are grown in this district include sorghum, maize, barley and groundnuts, in addition to variety 
of cash crops such as onions, sweet potatoes, peas and chat. According to the district office of Agriculture and Rural Development, the total livestock population of the district is estimated to be around 225,398 Heads out of this 33,705 are cattle, 73,489 are camels, 108,000 are goats \&sheep and 10204 are others.

Rural livelihoods in this district is increasingly vulnerable to risks posed by weather and climate change due to this farmers often sell their productive assets that they need to farm, such as Oxen, in order to survive the poor harvest and drought seasons. In this study area farmers do not invest more, due to the fact that in the most droughts prone areas of the country farmers may reduce investments in good seasons because they fear that they will lose the investment if a drought occurs (OXFAM, 2013). According to Babile district disaster risk profiling programme, drought is the major disaster risk in this area following by livestock, human diseases and environmental degradation (deforestation and soil erosion). In addition, lack of irrigation, poor access to agricultural inputs, veterinary services and health stations; high illiteracy level, poor preparedness measures toward the disaster are major vulnerability factors that limited household alternative livelihood sources in the district.

\subsection{Objective of the Study}

The overall objective of this study is to evaluate the impact of PSNP on household livelihood, whereas the specific objectives;

1. To examine the impact of Productive Safety Net Programme on household consumption

2. To examine the impact of Productive Safety Net Programme on household annual income

\subsection{Data Collection Methods and Analysis}

The study used primary data collected from the two Kebeles in the study area collected the period between January/12/2017 up to February/ 6/ 2017 in the district. After selecting the district purposively due to its wide coverage of the programme and expediency to the researcher, three-stage stratified random sampling technique was employed and a total of 160 households were randomly and proportionately selected for the analysis.

The program impact analysis for this study used both descriptive statistics and econometric model. The fundamental problem for a quantitative impact evaluation of a program like the PSNP is that only what happens to beneficiaries who are receiving benefits is observable; in which what would happen to the same households if they did not receive benefits do not observe. This is called the problem of the counterfactual. A second issue is selection bias. Selection bias arises when beneficiaries differ in some systematic way from non-beneficiaries. The ability of the researcher to make statements about the causal impact of the PSNP rests on how well we can address these two problems (Berhane et al., 2017).

Therefore, this study used Propensity score matching (PSM) method which is the most widely used matching method in program impact evaluation currently. PSM uses a fully nonparametric technique to estimate the outcome model. Lastly, to quantify empirical results of this study Statistical Soft-ware STATA version 13 and SPSS version 20 were used for data analysis, and coding and entering respectively.

\subsubsection{Propensity Score Matching (PSM) Method}

In the current program impact evaluation PSM is one of the most commonly used methods when there is a lack of baseline survey and random assignment of treatments to subject is not feasible. PSM refers to the pairing of treatment and control groups with similar values on the propensity score, and possibly other covariates (Rubin, D.B., 2001).

The dependent variable of interest for this study was program participation which has binary nature by taking a value of 1 and 0 . Assessing the impact of any intervention requires making an inference about the outcomes that would have been observed for participants if they had not participated in the program. The appropriate evaluation of the impact of the program requires identifying the average treatment effect on the treated (ATTs) defined as the difference in the outcome variables between the treated households and their counterfactual. According to Rosenbaum, P. R., (2002) counterfactual refers to what would have happened to the outcome of program participants if they had not participated in the treatment.

In case of binary treatment of the program the treatment indicator $D_{i}$ equals one if individual $i$ receives treatment and Zero otherwise. The potential outcomes are then defined as:

$Y i(D i)$ For each individual $i$, where $i=1,2, \ldots \ldots n$, then the treatment effect of individual $i$ can be articulated as:

(1) $T i=Y i(1)-Y i(0)$

Estimating individual treatment effect $T i$ is not possible. Therefore, Average (population) treatment effect on the treated (ATT) is developed which specified as:

$$
\text { (2) } \begin{aligned}
& T_{A T T}=E(T \mid D=1)=E[Y(1) \mid D=1]- \\
& E[Y(0) \mid D=1]
\end{aligned}
$$

Therefore, the counterfactual mean for those being treated represented as:

$-E[Y(0) \mid D=1]$, that is actually not observed

$$
\text { (3) } \begin{gathered}
A T T=E[Y(1) \mid D=1]-E[Y(0) \mid D=0]=T_{A T T}+ \\
E[Y(0) \mid D=1]-E[Y(0) \mid D=0]
\end{gathered}
$$

$T_{A T T}$ Is so-called 'self-selection bias' then the true parameters of $T_{A T T}$ is only identified if

(4) $E[Y(0) \mid D=1]-E[Y(0) \mid D=0]=0$

(5) $T_{A T T}=E[Y(1)-Y(0)]$

Common support region given by:

(6) (overlap) $0<p(D=1 \mid X)<1$

Lastly the general PSM model specified as a fallow: 


$$
\text { (7) } \begin{aligned}
& T_{A T T}=E p(x) \mid D=1\{E[Y(1) \mid D=1, p(x)]- \\
& E[Y(0) \mid D=0, p(x)]\}
\end{aligned}
$$

Therefore, ATTs is simply the mean difference in outcomes over the common support; appropriate weighted by the propensity score distribution of participants.

\subsubsection{Binary Logit Model Specification}

Adopting from Gujarati, D.N. (2004) the logistic distribution function for the determining factors in livelihood status of the households is specified as follows:

(8) $P i=E(y=1 \mid x 1)=\frac{1}{1+e^{(\beta o+\beta 1 x 1)}}$

Equation (1) can be simplified as:

$$
\text { (9) } P i=\frac{1}{1+e^{-z i}}
$$

The probability that a given household is affected by PSNP participation (participant) is expressed by equation (2) while, the probability for not being affected (non-participant) is:

$$
\text { (10) } 1-P i=\frac{1}{1+e^{z i}}
$$

Therefore, the odds ratio can be written as:

$$
\text { (11) } \frac{P(i)}{1-P(i)}=\frac{1+e^{Z(i)}}{1+e^{-Z(i)}}=e^{z i}
$$

Now ( $\mathrm{Pi} / 1-\mathrm{Pi})$ is simply the odds ratio in favor of participating in PSNP; the ratio of the probability that a household would be influenced by the program to the probability of that they are not influenced. Finally, taking the natural logarithms of the odds ratio of equation (4) would result the logit model as indicated below.

$$
\text { (12) } L i=\ln \left(\frac{P(i)}{1-P(i)}\right)=\ln \left[e^{z i}\right]=Z_{i}
$$

Where: $\mathrm{Z} \mathrm{i}=$ is a function of $\mathrm{n}$ explanatory variables (Xi) which is also expressed as:

$$
\text { (13) } Z i=\beta o+\beta 1 \times 1+\beta 2 \times 2+\cdots+\beta n X n
$$

Where: $\beta 0$, is an intercept, $\beta 1, \beta 2 \ldots ., \beta \mathrm{n}$ are slopes of the equation in the model. $\mathrm{Li}$ is log of the odds ratio, which is not only linear in $\mathrm{X}$ but also linear in the parameters. $\mathrm{Xi}$ is vector of explanatory variables. Finally, disturbance term $\mu i$ which is unobserved factors are taken into account and the logit model becomes:

$$
\text { (14)(14) } Z i=\beta 0+\beta 1 X 1+\beta 2 X 2+\cdots+\beta n X n+\mu i
$$

\subsection{Variables and Their Specific Measurements}

Table 1. Summary of study variables.

\begin{tabular}{lll}
\hline Variable & Type and definition & Measurement \\
treatment & Dummy, participation in PSNP & 1 if yes, 0 otherwise \\
Food intake & Continuous, calorie intake in Kcal/AE & Calorie \\
Annual income & Continuous, annual income in ETB & Birr \\
Age & Continuous, age of household head & Full years \\
Sex & Dummy, sex of household head & 1 if male, 0 otherwise \\
EDL & Continuous, education level HH head & Full years of schooling \\
FMS & Continuous, family size & HH member numbers \\
FRMS & Continuous, farm land owned & Hectare \\
LOW & Continuous, livestock ownership & TLU \\
RM & Dummy, roofing type of household & 1 if grass, 0 otherwise \\
DMP & Continuous, distance from nearest market & Km \\
DR & Continuous, number of dependents & Number of members \\
DEXS & Continuous, distance of extension services & Km \\
DPW & Continuous, distance from portable water & Km \\
\hline
\end{tabular}

Source: Author's compilation, 2017.

\section{Results and Discussion}

\subsection{Study Results of Descriptive Statistics}

\subsubsection{Age of the Households}

The mean age of the sample household heads was found to be 39.67 years. The mean age of program participants and non- participants were 41.31 and 38.32 years, respectively. The age mean difference between treatment and control groups was significant $(\mathrm{p}=0.004)$ with $\mathrm{t}$-value $(\mathrm{t}=2.86)$.

\subsubsection{Sex of the Household Heads}

The study finding shows total sampled households of
55.56 percent and 44.44percent were male and female headed household in the study area, respectively. Male headed households represent about 20.37percent and 35.19percentfor PSNP treatment and control group households respectively. Where, female headed households represent about 40percent and 32 percent for PSNP participant and non-participant households respectively. Therefore, sex mean difference is statistically significant $(\mathrm{p}=0.016)$ with $\chi 2=5.76$.

\subsubsection{Family Size}

The mean family size of sampled households was 6.73 and the mean family size of PSNP treatment households was 7.57 where as 6.03 for control group households. The finding 
result of the study showed a difference in mean family size of PSNP participants and non-participants was highly significant (at 1 percent probability level).

\subsubsection{Educational Status}

The mean education level of sample households was 3.56years of schooling, whereas the mean education level of PSNP treatment and control group households was 4.23 and 3.01years of schooling respectively. The statistical analysis for education level revealed that there is significant mean difference between treatment and control groups (at 5 percent probability level).

\subsubsection{Distance from the Nearest Market}

The mean distance for the sampled households to the nearest market place was $49.72 \mathrm{Km}$ where PSNP treatment and control group households' time taken to reach nearest market was 59.10 and $42.02 \mathrm{Km}$ respectively. This mean difference between the treated and controls group was highly significant (at 1 percent).

\subsection{Results of Econometric Model}

\subsubsection{Estimation of Propensity Scores}

Binary logit model was used to estimate the propensity scores of respondents which help us to perform matching algorithm between the treated and control groups in the study area. In estimating the propensity scores, data from both groups were pooled such that the dependent variable takes a value of 1 if the household was program participant and 0 otherwise.

The pseudo-R2 value of 0.25 shows that, the estimated model performs well for the intended matching exercise. A low pseudo-R2 value means program treatment households do not have many distinct characteristics from control households and this finding shows that there is good match between the two groups based on pre-intervention characteristics. According to table 2 among 11 variables included in the model 5 are statistical significance such age, sex, family size, distance from nearest market place and distance from portable water at 1 percent, 10 percent, 1 percent, 10 percent and 5 percent level of significance respectively. However, among explanatory variables included in the model six variables were found to have no significant influence on household calorie intake and annual income hence on households' livelihood status. But, the sign of the distance from portable water variable was unexpected.

Table 2. Estimated logistic regression result.

\begin{tabular}{lllll}
\hline Model variables & Coef. & $\begin{array}{l}\text { Std. } \\
\text { Err. }\end{array}$ & z-value & $\begin{array}{l}\mathbf{P}>|\mathbf{z}|- \\
\text { value }\end{array}$ \\
\hline Age & $0.098^{* * *}$ & 0.032 & 3.08 & 0.002 \\
Sex & $1.033^{*}$ & 0.413 & 2.5 & 0.012 \\
Educational level & 0.057 & 0.057 & 0.99 & 0.32 \\
Family size & $0.270^{* * *}$ & 0.087 & 3.11 & 0.002 \\
Farm size & -0.168 & 0.219 & -0.77 & 0.442 \\
Livestock in TLU & 0.073 & 0.079 & 0.92 & 0.355 \\
Dependent ratio & -0.276 & 0.203 & -1.36 & 0.173 \\
\hline
\end{tabular}

\begin{tabular}{lllll}
\hline Model variables & Coef. & $\begin{array}{l}\text { Std. } \\
\text { Err. }\end{array}$ & z-value & $\begin{array}{l}\mathbf{P}>|\mathbf{z}|- \\
\text { value }\end{array}$ \\
\hline $\begin{array}{l}\text { Distance from nearest market } \\
\text { Distance from portable water }\end{array}$ & $\begin{array}{l}0.020^{*} \\
-0.028^{* *}\end{array}$ & 0.008 & 2.59 & 0.014 \\
$\begin{array}{l}\text { Distance from extension } \\
\text { service }\end{array}$ & 0.020 & 0.014 & 1.49 & 0.056 \\
Roofing type & -0.631 & 0.438 & -1.44 & 0.137 \\
cons & -7.329 & 1.888 & -3.88 & 0.00 \\
Sampled households & 162 & & & \\
LR chi2 (11) & 55.86 & & & \\
Prob>chi2 & 0.000 & & & \\
Pseudo R2 & 0.25 & & & \\
Log likelihood & -83.567 & & & \\
\hline
\end{tabular}

Source: Own estimation result, 2017.

$* * *, * *, \& *$ indicates significance at $1 \%, 5 \%$ and $10 \%$ probability levels, respectively

After running the model and propensity score is estimated as indicated in Table 3 below, the program participant households' propensity score was varied between 0.114 and 0.975 with mean propensity score of 0.615 , while control group households' propensity score varied between 0.017 and 0.913 with the mean of 0.451 . Therefore, based on this calculated propensity score common support region $(0.114$ 1nd 0.913 ) was developed by using minimum and maximum criteria and any household that have below minimum and above maximum was discarded from the sample.

Table 3. Estimated Propensity Scores Distribution.

\begin{tabular}{|c|c|c|c|c|c|}
\hline Group & Observation & Mean & $\begin{array}{l}\text { Std. } \\
\text { Dev. }\end{array}$ & Min & Max \\
\hline $\begin{array}{l}\text { Participants } \\
\text { Households }\end{array}$ & 73 & 0.615 & 0.227 & 0.114 & 0.975 \\
\hline $\begin{array}{l}\text { Non -participants } \\
\text { Households }\end{array}$ & 89 & 0.316 & 0.235 & 0.017 & 0.913 \\
\hline Total Households & 162 & 0.451 & 0.275 & 0.017 & 0.975 \\
\hline
\end{tabular}

Source: Own estimation, 2017.

To conduct ATTs different matching algorithms are available among these matching algorithms the one with best estimates of propensity score should be selected. The choice of matching method involves a trade-off between matching quality and its variance. Various matching estimators have been suggested in the impact evaluation literatures. The most commonly used matching methods in the use of PSM include the nearest neighbor matching, radius (caliper) matching, and kernel matching estimators.

According to Caliendo, M., and S. Kopeing (2008) the final choice of a matching estimator was guided by three basic criteria such as balancing test, pseudo- $\mathrm{R}^{2}$ and matched sample size. Specifically, a matching estimator which balances all explanatory variables (i.e., results in insignificant mean differences between the two groups), bears a low $\mathrm{R}^{2}$-value and results in large matched sample size is the most appropriate estimator. Based on the above mentioned criteria alternative matching estimators were tried in matching the treatment and control households based on the common support region for this specific study. Finally, according to Table 4, kernel matching with a band width of 0.25 was selected based on 
performance criteria. Therefore, the estimation results and discussion for this study are the direct outcomes of the kernel matching algorithm based on a band width of 0.25 .

Table 4. Choosing criteria among different matching estimators.

\begin{tabular}{llll}
\hline \multicolumn{4}{l}{ Choosing criteria of matching } \\
\hline Matching estimator & Balancing test* & Pseudo- R ${ }^{2}$ & $\begin{array}{l}\text { Matched sample } \\
\text { size }\end{array}$ \\
\hline Nearest Neighbor & & \\
NN(1) & $10 / 11$ & 0.043 & 134 \\
NN(2) & $10 / 11$ & 0.041 & 134 \\
NN(3) & $10 / 11$ & 0.035 & 134 \\
Radius caliper & & & \\
0.01 & $11 / 11$ & 0.042 & 90 \\
0.25 & $11 / 11$ & 0.022 & 90 \\
Kernel & & & \\
band width(0.5) & $12 / 13$ & 0.046 & 83 \\
band width(0.25) & $11 / 11$ & 0.015 & 134 \\
\hline
\end{tabular}

Source: Own estimation, 2017.

\subsubsection{Treatment Effect on the Treated (ATT)}

The study results presented in table 5 revealed that the Productive Safety Net Program (PSNP) intervention has enabled the program treatment households to preserve their food security status. The study revealed that the program has positive and highly statistically significant impact on calorie intake which is one of the most widely used proxy measure of food security status in recent literatures. After controlling for pre-intervention differences in characteristics of the PSNP participant and nonparticipant households, it was found that, on average, the program has increased calorie intakes/food security status of the participating households by $1269.68 \mathrm{Kcal} / \mathrm{AE}$, and this shows that due to PSNP intervention, the treated household's food calorie intakes increased by more than half $(55.08 \%)$ as compared to the controlled households and this impact was highly significant(at 1 percent probability level).

According to table 5 presented results households' annual income was found to be statistically insignificant. This is mainly due to the previous program transfers system which focuses only on food distribution, but currently the government of Ethiopia with international funding agents has reshaped the types of beneficiary transfers by adding cash transfer intended to build the household livelihood capacity which is new to the programme.

Table 5. Results of average treatment effects on treated.

\begin{tabular}{|c|c|c|c|c|c|c|}
\hline Variable & Sample & Treated & Controls & Difference & S.E. & T-stat \\
\hline Calorie intake & ATT & 3573.08 & 2303.97 & 1269.11 & 186.68 & $\begin{array}{l}6.80 * * \\
*\end{array}$ \\
\hline $\begin{array}{l}\text { Monthly } \\
\text { income }\end{array}$ & ATT & $\begin{array}{l}17611.7 \\
6\end{array}$ & $\begin{array}{l}17358.1 \\
2\end{array}$ & 253.64 & 1270.03 & $0.20 \mathrm{NS}$ \\
\hline
\end{tabular}

Source: Own estimation, 2017.

*** indicates significance at 1 percent level, \& NS stands for statistically insignificant

\subsubsection{Sensitivity Analysis}

Sensitivity of the evaluation was undertaken to detect whether the identification of conditional independence assumption was satisfactory or affected by the dummy confounder or the estimated ATT is robust to specific failure of the CIA. As indicated in Table 6, this study results concluded that the program impact estimators (ATTs) are insensitive to unobserved selection bias. Therefore, it is pure effect of PSNP interventions in this district.

Table 6. Sensitivity analysis using Rosenbaum bounding approach.

\begin{tabular}{|c|c|c|c|c|c|c|c|c|c|}
\hline \multicolumn{10}{|c|}{ p-critical values (the upper bound of Wilcoxon significance level (Sig + ) at different critical value of Gamma(e $\gamma)$} \\
\hline Outcome & $\mathbf{e}^{\gamma}=\mathbf{e}^{\gamma}=\mathbf{1}$ & $\mathrm{e}^{\gamma}=\mathbf{1 . 2 5}$ & $\mathrm{e}^{\gamma}=\mathbf{1 . 5}$ & $\mathrm{e}^{\gamma=1.75}$ & $\mathbf{e}^{\gamma}=\mathbf{2}$ & $\mathrm{e}^{\gamma}=\mathbf{2 . 2 5}$ & $\mathrm{e}^{\gamma}=\mathbf{2 . 5}$ & $\mathrm{e}^{\gamma}=\mathbf{2 . 7 5}$ & $\mathbf{e}^{\gamma=\mathbf{3}}$ \\
\hline $\mathrm{Kcal} / \mathrm{AE}$ & 0 & 0 & 0 & 0 & $3.0 \mathrm{e}-15$ & $9.2 \mathrm{e}-14$ & $1.5 \mathrm{e}-12$ & $1.4 \mathrm{e}-11$ & $9.2 \mathrm{e}-11$ \\
\hline
\end{tabular}

Source: Own estimation, 2017. In which ey (Gamma) =log odds of differential due to unobserved factors where Wilcoxon significance level for the significant outcome variable (Calorie intake) is calculated.

\section{Conclusion}

This study used both descriptive statistics and econometric techniques (PSM) to analyze the empirical data that were collected from treatment and controls group in the study area.

This study found that among eleven explanatory variables included in the model five of them are statistical significance including age, sex, family size, distance from nearest market place and distance from portable water. In which, Ages, sex, family size and distance from nearest market have positive significance influence on the program participation decisions. But, the sign of the distance from portable water variable was unexpected which shows negative influence on program participation decisions.

After controlling for pre intervention differences in demographic, location, institutional and socio-economic characteristics of the treatment and control households, the study findings shows that, average calorie intake for treatment and control group farmers were 3573.08 and $2303.97 \mathrm{Kcal} / \mathrm{AE}$, respectively, and the difference of 1269.11 $\mathrm{Kcal} / \mathrm{AE}$ was found due to the program intervention in the study area. However, the result shows that there is no significant difference among treatment and control group in terms of annual income. Therefore, the findings of this study revealed that household participation in PSNP has positive and statistically significant influence on food consumption, so that on household livelihood in the study area.

The population in this study area has not the same accessibility of assets which influence their livelihood status and livelihood strategies that they undertake. Therefore, PSNP needs to understand these rural households' conditions because different categories of people have different priorities, and they may respond differently to PSNP and other government development interventions. 


\section{References}

[1] Abduselam A. (2017), "Food Security Situation in Ethiopia: A Review Study. International Journal of Health Economics and Policy". Vol. 2, No. 3, 2017, pp. 86-96. doi: 10.11648/j.hep.20170203.11.

[2] Berhane et al., (2017), "The impact of Ethiopia's Productive Safety Net Programme on the nutritional status of the children: 2008-2012”. ESSP working paper 99. EDRI \& IFPRI. Addis Ababa, Ethiopia.

[3] Caliendo, M., and S. Kopeing (2008), "Some Practical Guidance for the Implementation of Propensity Score Matching”. IZA Discussion Paper No. 1588, University of Cologne.

[4] Catley et al., (2016), "USAID/Ethiopia Agriculture Knowledge, Learning, Documentation and Policy Project". No. 663-13-000006: implemented by the Feinstein International Center, Friedman School of Nutrition Science and Policy, Tufts University.

[5] CSA (2007), "Population and Housing Census Report. Ethiopia. Statistical Agency". Retrieved Nov 28, 2013 (Doc\Reports\National_Statistical.pdf).

[6] DIE (2016), "The Impact of Cash Transfers on Food Security in Sub-Saharan Africa: Evidence, Design and Implementation: German Development Institute/Deutsches Institut für Entwicklungspolitik (DIE) Tulpenfeld 6-53113 Bonn, Germany.
[7] Gujarati, D. N. (2004), "Basic econometric book, Fourth Edition": McGraw-Hill, New York.

[8] MoARD (2009), "Food Security Programme, 2010-2014". Addis Ababa, Ethiopia: MoARD.

[9] MoARD (2015), "Productive safety net programme/PSNP-4. Joint review \& Implementation Support Mission: November 23-Decemper 4, 2015, AIDE MEMOIRE.

[10] Mulugeta T., Mengistu B., Delelegne E., (2006), "Ethiopia Productive Safety Net Programme (PSNP). The PSNP Policy, Programme and Institutional Linkages, Final report, 2006. IDLgroup, UK.

[11] OXFAM (2013), "Managing risks to Agricultural Livelihoods": Impact evaluation of the Harita program in Tigray, Ethiopia, 2009-2012. Policy \& advocacy office 1100 15 th street, NW, suite 600 Washington, DC.

[12] Rosenbaum, P. R., (2002), “Observational Studies. 2nd ed. New York": Springer.

[13] Rubin, D. B. (2001), "Using Propensity Scores to Help Design Observational Studies": Application to the Tobacco.

[14] United States Department of States (2011), "Bureau of African Affairs, Background Note": Ethiopia. http://www.state.gov/r/pa/ei/bgn/2859.htm. (Accessed on 24 June, 2011). 